\title{
O IMPOSTO SOBRE CIRCULAÇÃO DE MERCADORIAS E O INSTITUTO DA SELETIVIDADE
}

\author{
THE TAX ON COMMODITIES AND THE \\ SELECTIVITY INSTITUTE
}

\begin{abstract}
Lívia Luiza do Rego Barros ${ }^{2}$
RESUMO: O objetivo deste artigo é apresentar o instituto da seletividade que o Inciso III do Parágrafo $2^{\circ}$ do Artigo 155 da Constituição Federal estabelece para as operações tributáveis pelo Imposto sobre Operações Relativas à Circulação de Mercadorias e sobre Prestação de Serviços de Transporte Interestadual e Intermunicipal e de Comunicação (ICMS). Procura-se demonstrar que o instituto da seletividade, que muitos denominam princípio, pode ser instrumento de efetivação de justiça tributária e, assim, contribuir para que se alcance plenamente o ideal de justiça digno de um Estado Democrático de Direito. Para tanto, são traçadas algumas considerações sobre o histórico dos impostos no Brasil; breve e genericamente, são apresentados marcos reguladores do imposto e dados atuais sobre sua importância e inserção na esfera econômica do Estado e dos contribuintes. Ao final, são tecidas considerações sobre a contribuição que o instituto oferece para a efetivação da federação de cooperação no Brasil e para o fortalecimento da aplicação do princípio da capacidade contributiva.

Palavras-Chave: Capacidade Contributiva; ICMS; Justiça; Seletividade; Tributação.

ABSTRACT: The aim of this paper is to present the selectivity institute that Item III of Paragraph 2 of Article 155 of the Federal Constitution provides for taxable purposes by Tax Operations Related to the Circulation of Goods and on Services of Interstate and Intermunicipal Transportation and Communication (ICMS). It seeks to demonstrate that the selectivity institute, which many call principle, can be an instrument of realization of tax justice and, thereby, contribute to reaching the full ideal of justice worthy of a democratic state of law. To do so, present some considerations about the history of taxes in Brazil; briefly and generally are presented regulatory frameworks of tax and present data on its role and importance in the economic sphere of the state and taxpayers. Finally, some considerations about the contribution that the institute provides for effective cooperative federation in Brazil and to strengthen the principle of ability to pay.

Palavras-Chave: Ability to pay; ICMS; Justice; Selectivity; Taxation.
\end{abstract}

Letícia Buzzo $^{1}$

Natália Leite ${ }^{3}$

\footnotetext{
1 Bacharelanda em Direito da Universidade Estadual de Londrina.

2 Bacharelanda em Direito da Universidade Estadual de Londrina.

3 Bacharelanda em Direito da Universidade Estadual de Londrina
} 


\section{HISTÓRICO}

A história da tributação no Brasil remonta à chegada dos portugueses que, seguindo modelo muçulmano, desde o século XIV, exigiam dos súditos de sua colônia um quinto ou vintena $(20 \%)$ de todas as tomadas, tesouros ou descobertas que se fizessem no reino lusitano (SOUZA, 1950, p. 94).

Enquanto colônia, o Brasil submetia-se ao regramento português, que era composto basicamente por Ordenações (Afonsinas e Manuelinas, constituídas por compilações de normas do Direito Romano e Canônico, principalmente), Cartas de Lei (normas de caráter geral), Alvarás (normas de caráter específico) e Cartas Régias (resoluções do rei sobre a autoridade pública). Ainda sobre o período colonial, é importante ressaltar que a Coroa Portuguesa instituiu a figura do Provedor Mor da Real Fazenda, cuja função era cuidar da arrecadação de tributos.

O atual Imposto sobre Operações Relativas à Circulação de Mercadorias e sobre Prestação de Serviços de Transporte Interestadual e Intermunicipal e de Comunicação (ICMS) assumiu as características atuais em 1965, mas ele pode ser visto no Brasil Colônia quando se verifica que a saída e a entrada de mercadorias no e do país recebia tributação e, também, a circulação interna de mercadoria, se a coroa portuguesa alcançasse o comércio efetivado.

Com a abertura dos portos às nações amigas (ou inimigas de Napoleão, conforme o ponto de vista), em 1808, a necessidade de arrecadação aumentou, pois, além de Portugal estar enfrentando uma guerra na Europa, a permanência da Corte no Rio de Janeiro criou necessidades e despesas que o colonizador não tinha até então (alguns historiadores relatam que o preço do aluguel de imóveis chegou a ficar 20 vezes mais caro). A necessidade de arrecadar fez com que fossem criados novos impostos e taxas majorados os até então existentes.

A primeira constituição brasileira, de 1831, foi outorgada por Dom Pedro I e, em matéria tributária, pouco inovou.

O mesmo parece ter ocorrido com a primeira Constituição Republicana, de 1891, que dedicou os artigos 5 a 12 à matéria tributária, enfatizando as competências para tributar de cada ente federado. Naquela Constituição, mantiveram-se as "taxas de selos", que já existiam na Colônia e no Reinado de Pedro I e Pedro II.

As duas grandes guerras ocorridas no Século XX, e os motivos que a elas levaram, explicitaram a necessidade de novas formas de se praticar a política e as formas de se constituir um Estado, com fixação de atribuições ao ente público, com o intuito de se evitar que os fatos tenebrosos que aconteceram no planeta jamais voltassem a se repetir. Um dos frutos das 
lições aprendidas nas grandes guerras foi a necessidade de se instaurar estados que tivessem capacidade de prover seus cidadãos em casos de risco social. Em breves palavras, os eventos dos anos 1914 a 1946 são o pano de fundo que permite entender a necessidade constatada de se implantar o chamado Estado de Bem Estar Social, um Estado que promovesse a educação e a saúde e fornecesse amparo aos cidadãos que necessitassem da previdência social por se encontrarem em situação de risco social. Tudo isto visando impedir que novos eventos abomináveis voltassem a se repetir.

A Europa tendo aprendido a duras penas que os problemas econômicos geram problemas políticos e sociais, cuidou de criar esse modelo de Estado. Surgiu, então, a constatação da necessidade do planejamento econômico. Segundo o historiador Tony Judt (2008, p. 86):

\begin{abstract}
A economia de planejamento seguiu de perto as lições aprendidas nos anos 30 - uma estratégia bem-sucedida para recuperação no pós-guerra deve evitar qualquer retorno à estagnação econômica, à depressão, ao protecionismo e, sobretudo, ao desemprego. Considerações idênticas pautaram a criação do moderno Estado previdenciário Europeu. De acordo com o saber corrente na década de 1940, as polarizações políticas dos dez anos que compreenderam o período entre as duas guerras foram geradas, diretamente, pela depressão econômica e por seu custo social. [...] Mas o "Estado Previdenciário" - planejamento social - era mais do que um profilático contra a instabilidade política. [...] Havia bastante consenso [já em 1945] de que as condições físicas e morais dos cidadãos eram assunto de interesse comum e, portanto, responsabilidade do Estado.
\end{abstract}

Tornou-se preciso, então, tributar. Mais ainda, era preciso tributar de forma inteligente, propiciando recursos ao Estado para oferecer um sistema sólido de bem estar social, sem com isto onerar demasiadamente o contribuinte, para não correr o risco de se resolver um problema criando-se outro, quiçá maior.

Nesse cenário, ganham relevo institutos como a progressividade e a seletividade na tributação. Esses dois elementos, a partir da segunda metade do século XX, passaram a integrar os sistemas tributários da maioria dos países ocidentais, inclusive o Brasil, no qual os dois institutos também foram recepcionados pelo sistema jurídico tributário. No caso do ICMS, a progressividade não encontra aplicação ampla, como encontra no caso do Imposto de Renda, por exemplo. O instituto da seletividade se efetivará através da diferenciação das alíquotas, como será tratado a seguir. 


\section{OS MARCOS LEGAIS DO ICMS}

Diferentemente de outros tributos, que podem ser denominados de estáticos - como aqueles que incidem sobre a propriedade, como o Imposto Territorial Rural (ITR) ou o Imposto sobre a Propriedade de Veículos Automotores (IPVA), ou seja, tributos incidentes sobre riqueza já produzida e estabilizada -, o Imposto sobre Operações Relativas à Circulação de Mercadorias e sobre Prestação de Serviços de Transporte Interestadual e Intermunicipal e de Comunicação (ICMS) pertence à classe daqueles tributos denominados "dinâmicos", como o Imposto sobre a Renda (IR) e o Imposto sobre Produtos Industrializados (IPI), ou seja, incidem sobre a dinâmica da economia de uma coletividade, representando as riquezas em produção em um dado período (SCHMITT, 2005, p. 15-16).

Talvez por situar-se na esfera dinâmica da economia e da sociedade, o ICMS encontra-se regulado em inúmeros normativos, principalmente ao se considerar que cada estado da federação é responsável por sua regulação dentro de seus respectivos territórios. Em que pese haver disposição constitucional e lei de caráter nacional, especificamente leis complementares, regulando o ICMS, julga-se importante destacar os principais normativos que a ele se aplicam, enfatizando que, ainda que só se mencione a regulação paranaense, cada estado da federação possui suas leis, decretos e regulamentos que regem o tributo em seu território.

Necessário enfatizar que, por se tratar de tributo de competência estadual, dirigido àquele que talvez seja o setor mais dinâmico da economia contemporânea (operações que envolvem mercadorias), resulta que o ICMS encontra-se regido em inúmeros dispositivos legais, que vão desde preceitos e princípios constitucionais até resoluções do CONFAZ - Conselho Nacional de Política Fazendária e atos administrativos [executivos] de cada Secretaria da Fazenda Estadual da federação brasileira. Por isto, são oportunas as palavras de Bobbio (2000, p. 145):

\footnotetext{
A norma suprema - norma fundamental, não depende de nenhuma superior, e sobre ela repousa a unidade do ordenamento. Dá unidade a todas as outras normas, fazendo delas um conjunto unitário - o ordenamento. A ela remontam todas as fontes do direito. As normas constitucionais são produtoras das normas inferiores, isto é, produzem leis ordinárias que, por sua vez, produzem normas sobre outras matérias e executam, ou cumprem, outras regras. Todas as normas são, ao mesmo tempo, produtoras e executivas, com exceção da fase de grau mais alto e da fase de grau mais baixo de um ordenamento jurídico. A norma fundamental (grau mais alto) é somente produtiva e não executiva. Os atos executivos (grau mais baixo) são meramente executivos e não produtivos.
} 


\section{Normas nacionais}

O ICMS, como todos os tributos instituídos no Brasil, encontra seu marco normativo fundamental na Constituição Federal, mais especificamente em seu Art. 155, II e, como também, no Art. 34, Parágrafo $8^{\circ}$, do ADCT (Ato das Disposições Constitucionais Transitórias).

A regulamentação por meio de lei complementar, instituída pela $\mathrm{CF} / 88$ só aconteceu em 1997, através da Lei Complementar 87/1996, conhecida como Lei Kandir. Também se pode citar como marco regulatório do ICMS a Lei 5.172/66 (Código Tributário Nacional) que, apesar de não conter artigos específicos sobre o ICM (os artigos 52 a 58 foram revogados), disciplina de forma geral a tributação no Brasil.

\section{Normas estaduais}

Como mencionado, por se tratar de tributo de competência estadual, cada unidade da federação brasileira possui sua lei e seu regulamento do ICMS. No estado do Paraná, a Lei que disciplina o ICMS é a Lei 11.580, de 14 de novembro de 1996. De suma importância para a operacionalização do cálculo, recolhimento e estabelecimento das obrigações instrumentais, o RICMS (Regulamento do ICMS) foi instituído pelo Decreto n. 1.980 de 21 de dezembro de 2007, tendo sido atualizado diversas vezes, sendo a última em 13 de novembro de 2009, pelo Decreton. 5.750/2009. ORICMS encontra-se disponível no sítio eletrônico da Secretaria da Fazenda do Estado do Paraná e, até sua última atualização, consistia de arquivo em formato “pdf” que contava com 916 páginas.

\section{O princípio da seletividade}

Quando o Estado institui um tributo, o objetivo a ser alcançado é o "prover de dinheiro os cofres públicos, para que o Estado tenha os meios necessários à consecução dos fins que lhe são assinalados pela Constituição e pelas leis.” (CARRAZZA, 2003, p. 322). Assim, cumprindo a Constituição Federal, que institui o princípio da seletividade no ICMS em seu art. 155, §2 III, e tomando em consideração outro princípio do direito tributário, o da capacidade contributiva, os Estados membros da Federação instituem alíquotas diferenciadas em função da essencialidade dos produtos taxados, tributando com alíquotas maiores os produtos considerados supérfluos e com alíquotas menores os produtos considerados essenciais. 
O ICMS é um imposto que corresponde a cerca de $90 \%$ da receita de cada um dos estados brasileiros (MENESCAL, 2007) e ele incide sobre a circulação de mercadorias, em sentido genérico; por isto, atingiria ricos e pobres com a mesma intensidade, caso os entes públicos competentes para cobrá-lo não tomassem providências que levassem em consideração o Princípio da Capacidade Contributiva. Segundo este princípio, os que têm mais capacidade contributiva devem arcar com uma carga tributária maior do que aquela dirigida aos que têm menor capacidade contributiva. Este é o fundamento do princípio da seletividade no ICMS, que, segundo Carrazza (2003, p. 323),

[...] pode e deve ser utilizado como instrumento de ordenação político-econômica, estimulando a prática de operações ou prestações havidas por úteis ou convenientes para o país e, em contranota, onerando outras que não atendam tão de perto ao interesse nacional. É por isso, aliás, que, em algumas operações com produtos supérfluos, a alíquota aplicada é de $25 \%$ (o valor da operação) e, em outras, com produtos essenciais, as alíquotas baixam para $18 \%, 17 \%$ e, até, $12 \%$ e $9 \%$.

Segundo Menescal (2007), a essência do princípio da seletividade está inscrita na Constituição Federal e deve nortear todas as deliberações oriundas das assembléias legislativas no país:

\begin{abstract}
Seletividade quer dizer discriminação ou sistema de alíquotas diferenciadas por espécies de mercadorias. Trata-se de dispositivo programático, endereçado ao legislador ordinário, recomendando-lhe que estabeleça as alíquotas em razão inversa da imprescindibilidade das mercadorias de consumo generalizado. Quanto mais sejam elas necessárias à alimentação, vestuário, à moradia, ao tratamento médico e higiênico das classes mais numerosas, tanto menores devem ser. O discricionarismo honesto do legislador, fiel ao espírito da Constituição, fará a seleção das mercadorias e a relatividade das alíquotas.
\end{abstract}

\title{
CARACTERÍSTICAS DO ICMS QUE PERMITEM AAPLICAÇÃO DA SELETIVIDA- DE
}

Pode-se situar a origem do ICMnaLein ${ }^{\circ} 25(31.12 .1891)$ que instituiu o "Imposto de Consumo", de competência da União. Tal imposto incidia sobre alguns produtos, tais como bebidas, fumo e calçados, comalíquotas diferenciadas em função da destinação do produto. Em 1932, surgiu o Imposto sobre Vendas, instituído pelo Decreto n ${ }^{\circ} 22.061$ e, em 1934, com a então nova Constituição surgiu o IVC (Imposto sobre Vendas e Consignações), de competência dos Estados. Esses impostos encontravam forte rejeição por parte dos contribuintes em função de seu caráter cumulativo. 
O ICMS começou a tomar a feição que hoje apresenta em 1965, quando foi promulgada a Emenda Constitucional n ${ }^{\circ}$ 18/65. Por essa emenda, extinguiu-se o IVC e criou-se o ICM, determinando-se seu fato gerador como a circulação de mercadoria (operação mercantil). A competência para sua cobrança foi designada aos estados membros da federação e fixou-se a determinação de haver uniformidade de alíquotas para todas as mercadorias, além de se estabelecer que, em sua cobrança, prevalecerá o princípio da não-cumulatividade $\left(\operatorname{art} .12, \S 2^{\circ}\right.$, da EC 18/65).

A Constituição de 1988 ratificará o imposto, agora com a denominação de ICMS Imposto sobre Circulação de Mercadorias e sobre Prestação de Serviços de Transporte Interestadual e Intermunicipal e de Comunicação -, e fixará a competência de sua instituição aos estados, confirmando sua não-cumulatividade e determinando que haja deliberação por parte de Estados e Distrito Federal para que, através de convênio, regulem a matéria enquanto não promulgada Lei Complementar que a regule.

Nesse contexto, o Art. 155, Parágrafo $2^{\circ}$ da Constituição de 1988 prescreve que o ICMS será não-cumulativo e [inciso III], “poderá ser seletivo, em função da essencialidade das mercadorias e dos serviços".

Também no Artigo 155 da Constituição Federal de 1988, foi fixada a competência do Senado Federal como câmara de representação dos Estados federados, para, através de Resoluções, estabelecer alíquotas mínimas e máximas nas operações internas com mercadorias.

O CONFAZ - Conselho Nacional de Política Fazendária - constituído pelos Secretários Estaduais das Fazendas dos Estados Membros da Federação e pelo Ministro de Estado da República -, criado pela Lei Complementar 24/1975 para regular os convênios para a concessão de isenções, redução de base de cálculo e outros incentivos e favores fiscais em relação à tributação do ICM, posteriormente ICMS, possui poder normativo, também, sobre a matéria.

Antes da Constituição de 1988, o ICM era instrumento apenas de fiscalidade, entendida como a característica dos tributos de visarem arrecadar recursos para a manutenção do Estado e de suas atividades fim. Com a atual Constituição, o ICMS adquiriu características de extrafiscalidade, por força da instituição da seletividade a ele atribuída em função da essencialidade das mercadorias sobre as quais incide. Segundo Carrazza (2003, p. 322): 
alíquota do imposto sobre a importação de certos produtos voluptuários é altíssima. Isto ocorre não propriamente para aumentar a arrecadação, mas para que as pessoas se sintam desestimuladas a adquirir tais produtos, dando preferência aos similares nacionais.

Apesar do inciso III do parágrafo $2^{\circ}$ do Art. 155 da Constituição prever que o ICMS "poderá ser seletivo, em função da essencialidade das mercadorias e dos serviços”, o professor Roque Carrazza afirma que "este singelo 'poderá' equivale, na verdade, a um peremptório 'deverá'. Não se está aí, diante de uma mera faculdade do legislador, mas de uma norma cogente, de observância obrigatória". Isto por que, ao incidir sobre qualquer operação com mercadorias, o ICMS onera o contribuinte de fato, o consumidor, de todos e quaisquer produtos, impossibilitando que se cumpra o preceito, também constitucional, de observação da capacidade contributiva de quem arca com o tributo.

Para Chiesa (1997, p. 131) o instituto da seletividade, especificamente no caso do ICMS:

\begin{abstract}
Não só tem a função de levar dinheiro aos cofres públicos, mas também de ser um instrumento direcionador de condutas, servindo para fins extrafiscais. Assim, deve ser utilizado também para ordenar a política econômica, estimulando ou inibindo o consumo. Esse objetivo poderá ser atingido, v. g., tributando-se mais as mercadorias supérfluas do que os "gêneros de primeira necessidade". Além disso, poderá ser utilizado para conceder incentivos para um determinado setor da economia, como por exemplo, reduzir as alíquotas dos produtos agrícolas ou, ainda, inibir comportamentos, tributando com alíquotas elevadas, por exemplo, a venda de automóveis.
\end{abstract}

Cuidando para não confundir imunidade (sempre estabelecida em dispositivo constitucional) e isenção (caracterizada, doutrinariamente, como a dispensa legal de se pagar dado tributo), a seletividade pode ser obtida de diversas formas, tais como redução de alíquotas, variação na base de cálculo e incentivos fiscais.

Ainda há que se precaver quando do estabelecimento dos critérios para a implantação do instituto da seletividade. Neste sentido, são elucidativas as palavras de Carrazza (2003, p. 323):

Cumpre-se o princípio da seletividade comparando-se mercadorias ou serviços. Nunca, evidentemente, discriminando-se contribuintes, em função de raça, sexo, ocupação profissional etc., que a isto obsta o art. $5^{\circ}$, I, da CF. As mercadorias e os serviços de primeira necessidade devem, necessariamente, ser menos onerados, por via de ICMS, que os supérfluos ou suntuários. Por trás destas idéias está presente, em última análise, o princípio da capacidade econômica, pelo qual, quem, em termos econômicos, tem mais, há de ser mais onerado do que quem tem menos. 
Ainda com relação à seletividade, o professor Roque Carrazza defende que o melhor caminho para que ela se efetive é o do estabelecimento das alíquotas que irão incidir sobre a base de cálculo composta pela operação realizada com determinada mercadoria. Afirma ele:

\begin{abstract}
A seletividade, quer no IPI, quer no ICMS, poderá ser alcançada com o emprego de quaisquer técnicas de alteração quantitativa da carga tributária: sistema de alíquotas diferençadas, variação de bases de cálculo, criação de incentivos fiscais etc. Temos, porém - o que acaba sendo confirmado na prática -, que por intermédio da manipulação das alíquotas mais facilmente se alcança a seletividade, nestes impostos. [...] Evidentemente, o princípio da seletividade tem por escopo favorecer os consumidores finais, que são os que, de fato, suportam a carga econômica [...] do ICMS. Daí ser imperioso que sobre produtos, mercadorias e serviços essenciais haja tratamento fiscal mais brando, quando não total exoneração tributária, já que em relação a eles o adquirente, em rigor, não tem liberdade de escolha. (CARRAZZA, 2002, p. 83-4).
\end{abstract}

Estabelecido o conceito e os casos em que se impõe a aplicação do instituto da seletividade, apresenta-se, a seguir, o que vem ocorrendo no Estado do Paraná, visando estabelecer alguns parâmetros para discussão, em tópico posterior, da efetividade da aplicação da seletividade na área de abrangência do tributo em pauta, o ICMS.

\title{
A seletividade no caso do estado do paraná
}

O Estado do Paraná tem se destacado como aplicador do princípio da seletividade. A lei 11.580/1996, que regula o tributo na esfera de abrangência espacial do estado, apresenta alíquotas diferenciadas em função da essencialidade e, também, da destinação dos produtos que estão sendo tributados. À vista da referida lei, traçou-se o quadro 1, abaixo, que permite visualizar como se processa, no Paraná, a efetivação do dispositivo constitucional da seletividade.

\begin{tabular}{|l|l|}
\hline INTERNAS: & INTERESTADUAIS: \\
\hline 7\%: alimentos da merenda escolar. & $12 \%: \mathrm{rs}, \mathrm{sc}, \mathrm{sp}, \mathrm{mg}$, erj \\
\hline $\begin{array}{l}\text { 12\%: veículos, alimentos, disel, transportes, } \\
\text { agropecuários etc. }\end{array}$ & $7 \%:$ df e demais estados \\
\hline 18\%: regra geral. & $4 \%:$ transporte aéreo \\
\hline 25\%: armas, barcos, perfumes, etc. & \\
\hline 29\%: fumo e bebidas alcóolicas. & \\
\hline
\end{tabular}

Quadro 1 - Alíquotas de ICMS praticadas no estado do Paraná

Fonte: Lei 11.580/1996 - PR (atualizada até a Lei 16.016-PR, de 19.12.2008) 
Além disto, o Estado do Paraná também dá incentivos a práticas e ações que tenham por finalidade contribuir para a melhoria das condições de vida das classes economicamente desfavorecidas. Prova disto é a isenção [alíquota zero, neste caso] que o estado vem oferecendo, até 31/12/09, para componentes da "cesta básica da construção", desde que destinados às associações vinculadas a programas gerenciados pela Companhia Habitacional do Paraná (COHAPAR), que sejam utilizados na construção de casa populares, seguindo parâmetros de custo e de tamanho que garantam esta destinação.

\begin{tabular}{|c|c|c|}
\hline PRODUTO & ICM/ Paraná & $\begin{array}{l}\text { Se destinado a pro- } \\
\text { grama COHAPAR }\end{array}$ \\
\hline Areia & $\begin{array}{l}12 \% \text { (Art. 14, II, m, } \\
\text { 1, do Decreto 1.980/07) }\end{array}$ & zero \\
\hline Cal & $\begin{array}{r}12 \% \text { (Art. 14, II, m, } \\
\text { 4, do Decreto 1.980/07) }\end{array}$ & zero \\
\hline Cimento & 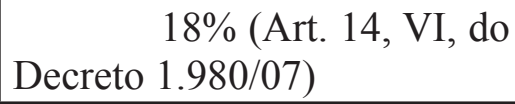 & zero \\
\hline Ferro & 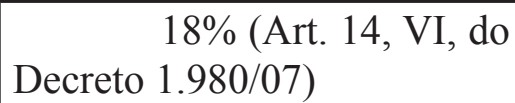 & zero \\
\hline Pedra & $\begin{array}{r}12 \% \text { (Art. 14, II, m, } \\
\text { 1, do Decreto 1.980/07) }\end{array}$ & zero \\
\hline Tijolos & $\begin{array}{r}12 \% \text { (Art. 14, II, m, } \\
\text { 2, do Decreto 1.980/07) }\end{array}$ & zero \\
\hline Telhas & $\begin{array}{r}12 \% \text { (Art. 14, II, m, } \\
\text { 2, do Decreto } 1.980 / 07 \text { ) }\end{array}$ & zero \\
\hline Louças Sanitárias & $\begin{array}{r}12 \% \text { (Art. 14, II, m, } \\
7 \text {, do Decreto 1.980/07) } \\
\end{array}$ & zero \\
\hline Janelas (ferro) & $\begin{array}{l}18 \% \text { (Art. } 14, \text { VI, do } \\
\text { Decreto } 1.980 / 07)\end{array}$ & zero \\
\hline Portas & $\begin{array}{l}12 \% \text { (Art. 14, II, n, } \\
\text { 4, do Decreto } 1.980 / 07 \text { ) }\end{array}$ & zero \\
\hline
\end{tabular}

Quadro 2 - Alíquotas de ICMS para "cesta básica da construção" no Paraná

Fonte: Convênios ICMS 61/93, 46/04, 10/04, 148/07 / Artigo inédito Prof ${ }^{\mathrm{a}}$ Marlene K. Bassoli.

\section{A não efetividade do instituto da seletividade}

Existe uma discussão doutrinária acerca do dispositivo constitucional da seletividade no caso do ICMS. O posicionamento do professor Carrazza, acima exposto, é de que a expressão "poderá ser seletivo" do inciso III, parágrafo segundo do Art. 155 da CF, é, na verdade, um 
“deverá ser seletivo" sempre que houver a caracterização da essencialidade das mercadorias e/ ou serviços tributados via ICMS. Mas esta interpretação não é unânime e, apesar de todas as legislações estaduais preverem alíquotas diferenciadas para produtos, em muitos casos essa diferenciação segue critérios outros que não o da essencialidade dos produtos. Isto pode ser verificado com a comparação inscrita no quadro abaixo, o qual lista alguns produtos e compara sua tributação no Estado do Paraná e no Estado de Rondônia.

\begin{tabular}{|c|c|c|}
\hline Produto & $\begin{array}{l}\text { Alíquota / Normati- } \\
\text { vo PARANÁ }\end{array}$ & $\begin{array}{l}\text { Alíquota / Normati- } \\
\text { vo RONDÔNIA }\end{array}$ \\
\hline Feijão & $\begin{array}{l}\text { Isento / Art. } 1^{\circ}, \mathrm{V}, \\
\text { Lei 14.978/05-PR }\end{array}$ & \begin{tabular}{|l}
$12 \%$ / Art.12, I, b,5, \\
Dec.8.321/98-RO
\end{tabular} \\
\hline Arroz & $\begin{array}{l}\text { Isento / Art. } 1^{\mathrm{o}}, \mathrm{I}, \text { Lei } \\
\text { 14.978/05-PR }\end{array}$ & $\begin{array}{l}\text { 17\% / Art.12, I, e, } \\
\text { Dec. 8.321/98-RO }\end{array}$ \\
\hline Pão Francês & $\begin{array}{l}\text { Isento/ Art } 1^{\circ}, \text { IX, } \\
\text { Lei } 14.978 / 05-P R\end{array}$ & \begin{tabular}{|l}
$17 \%$ / Art. 12, I, e, \\
Dec. 8.321/98-RO
\end{tabular} \\
\hline
\end{tabular}

Quadro 3 - Comparação de alíquotas de ICMS praticadas no Paraná e em Rondônia

Fonte: Legislação referida / Artigo inédito Prof ${ }^{a}$ Marlene K. Bassoli

Pode-se afirmar que a justiça tributária tem seu maior pressuposto no princípio constitucional da capacidade contributiva. Ocorre que, no caso do ICMS, não há como se estabelecer alíquotas em função da pessoa do comprador de uma mercadoria. Tal procedimento, além de ferir direito individual a não-discriminação, tornaria muito difícil, senão impossível, que as receitas estaduais operacionalizassem a cobrança do imposto. Apesar de "pobre também comprar perfume", resta evidente que perfume (tributado no Paraná pela alíquota de $25 \%$ ) é bem menos essencial que alimentos (tributados no Paraná pela alíquota, de um modo geral, de $12 \%$ ). De forma que o legislador estadual deve estar atento à dinâmica da sociedade e da economia de sua região quando for chamado a opinar sobre a seletividade no ICMS - que, muitas vezes, é imposta por decreto do executivo ou ato normativo da Fazenda Estadual. Sobre isto, vale trazer as palavras de Chiesa (1997, p. 132):

Destarte, sempre será possível, diante de uma situação concreta, analisados os elementos que a cercam, precisar se houve ou não uma violação ao princípio da seletividade, pois o conceito de essencial sempre vai estar associado às variantes de espaço e de tempo. [...] Assim, embora haja uma fluidez no conceito de "essencialidade", isso não lhe retira sua aplicabilidade imediata. Consequentemente, qualquer cidadão 
que se sentir prejudicado poderá recorrer ao Poder Judiciário para ver seus direitos assegurados.

Apesar da constatação do esforço despendido por parte do legislador constituinte e por parte de muitos legislativos estaduais, a carga tributária no Brasil parece onerar mais, proporcionalmente, os detentores de menor renda do que aqueles mais abastados. Tal afirmação encontra amparo nas palavras de Menescal (2007, p. 41-2) que, ao tratar da questão da "justiça fiscal" afirma:

A obtenção de uma estrutura tributária ideal, sob o ponto de vista da igualdade, da equidade e da justiça fiscal pode ocorrer por meio da aplicação dos princípios constitucionais de Direito Tributário, os quais possibilitam uma tributação mais justa, baseada na capacidade de contribuir de cada indivíduo. [...] A proteção aos direitos dos contribuintes surge, assim, respaldada pelos princípios constitucionais tributários, é o fundamento maior da justiça fiscal e o sentido da atividade tributária do Estado.

Ainda com foco no princípio da capacidade contributiva, apresenta-se o quadro 4, abaixo, retirado de publicação acadêmica de autoria de José Adrian Pintos-Payeras (UEL) e de Rodolfo Hoffmann (UNICAMP), que se encontra disponível no endereço eletrônico < http:// www.anpec.org.br/encontro2009/inscricao.on/arquivos/11258018da7d391d1a27a877389a23e c.pdf >, acessado em 15 de novembro de 2009, e que evidencia, com nitidez, que não só a carga tributária é, relativamente, maior para os detentores de menor renda quanto que o ICMS é o tributo no qual essa "injustiça tributária” se manifesta com maior ênfase. 


\begin{tabular}{|c|c|c|c|c|c|c|}
\hline $\begin{array}{l}\text { Classe de Ren- } \\
\text { da percapita } \\
\mathrm{R} \$ \text { de } \\
15 / 01 / 2003\end{array}$ & $\begin{array}{l}\text { Carga Ind. } \\
\text { sobre a } \\
\text { renda }(\%)\end{array}$ & ICMS (\%) & ISS (\%) & $\begin{array}{l}\text { PIS CO- } \\
\text { FINS (\%) }\end{array}$ & IPI (\%) & $\begin{array}{l}\text { \% Carga } \\
\text { Ind. e } \\
\text { Dispesa }\end{array}$ \\
\hline Até 120 & 24,57 & 13,33 & 0,35 & 8,43 & 2,45 & 17,07 \\
\hline $\begin{array}{l}\text { Maior que } 120 \\
\text { até } 240\end{array}$ & 20,39 & 11,03 & 0,38 & 6,80 & 2,18 & 16,76 \\
\hline $\begin{array}{l}\text { Maior que } 240 \\
\text { até } 360\end{array}$ & 18,07 & 9,82 & 0,40 & 5,93 & 1,92 & 16,29 \\
\hline $\begin{array}{l}\text { Maior que } 360 \\
\text { até } 480\end{array}$ & 16,72 & 9,12 & 0,44 & 5,43 & 1,73 & 15,79 \\
\hline $\begin{array}{l}\text { Maior que } 480 \\
\text { até } 600\end{array}$ & 15,99 & 8,66 & 0,48 & 5,19 & 1,66 & 15,16 \\
\hline $\begin{array}{l}\text { Maior que } 600 \\
\text { até } 720\end{array}$ & 15,52 & 8,47 & 0,47 & 5,02 & 1,57 & 15,18 \\
\hline $\begin{array}{l}\text { Maior que } 720 \\
\text { até } 960\end{array}$ & 14,83 & 7,98 & 0,51 & 4,79 & 1,55 & 15,02 \\
\hline $\begin{array}{l}\text { Maior que } 960 \\
\text { até } 1200\end{array}$ & 14,13 & 7,50 & 0,58 & 4,60 & 1,44 & 14,33 \\
\hline $\begin{array}{l}\text { Maior que } \\
1200 \text { até } 1440\end{array}$ & 12,99 & 6,91 & 0,49 & 4,18 & 1,41 & 14,49 \\
\hline $\begin{array}{l}\text { Maior que } \\
1440 \text { até } 1920\end{array}$ & 12,45 & 6,52 & 0,57 & 4,04 & 1,32 & 13,33 \\
\hline $\begin{array}{l}\text { Maior que } \\
1920 \text { até } 2640\end{array}$ & 11,58 & 6,04 & 0,57 & 3,77 & 1,20 & 12.77 \\
\hline $\begin{array}{l}\text { Maior que } \\
2640 \text { até } 3840\end{array}$ & 10,29 & 5,28 & 0,50 & 3,34 & 1,17 & 12,59 \\
\hline $\begin{array}{l}\text { Maior que } \\
3840 .\end{array}$ & 7,23 & 3,68 & 0,36 & 2,40 & 0,79 & 10,47 \\
\hline BRASIL & 14,10 & 7,53 & 0,46 & 4,62 & 1,48 & 14,51 \\
\hline
\end{tabular}

Quadro 4 - Carga tributária indireta sobre a renda familiar per capita, por imposto selecionado e sobre a despesa familiar per capita, segundo as classes selecionadas

Baseado nos microdados da Pesquisa de Orçamentos Familiares (IBGE) / 2002-2003 em conjunto com a legislação tributária. 
Também são esclarecedores os dados fornecidos pela organização "De olho no Imposto", acerca do percentual que, no preço final de uma mercadoria, vai para o fisco e não para o fabricante ou o vendedor do produto, conforme se pode ver no quadro abaixo:

\begin{tabular}{|c|c|}
\hline PRODUTO & $\%$ Tributos/preço final \\
\hline Mesa de madeira & $30,57 \%$ \\
\hline Motocicleta de até $125 \mathrm{cc}$ & $44,40 \%$ \\
\hline Motocicleta acima de $125 \mathrm{cc}$ & $49,78 \%$ \\
\hline Bicicleta & $34,50 \%$ \\
\hline Passagens Aéreas & $8,65 \%$ \\
\hline Transporte Rod. Interestadual Passageiros & $16,65 \%$ \\
\hline Transporte Rod. Interestadual Cargas & $21,65 \%$ \\
\hline Transporte Aéreo de Cargas & $8,65 \%$ \\
\hline MEDICAMENTOS & $36 \%$ \\
\hline CONTA DE ÁGUA & $29,83 \%$ \\
\hline CONTA DE LUZ & $45,81 \%$ \\
\hline CONTA DE TELEFONE & $47,87 \%$ \\
\hline Cigarro & $81,68 \%$ \\
\hline Gasolina & $57,03 \%$ \\
\hline Carne bovina & $18,63 \%$ \\
\hline Frango & $17,91 \%$ \\
\hline Trigo & $34,47 \%$ \\
\hline Arroz & $18 \%$ \\
\hline Óleo de soja & $37,18 \%$ \\
\hline Feijão & $18 \%$ \\
\hline Açúcar & $40,4 \%$ \\
\hline Leite & $33,63 \%$ \\
\hline Chocolate & $32 \%$ \\
\hline Sabão em barra & $40,50 \%$ \\
\hline Xampu & $52,35 \%$ \\
\hline Desodorante & $47,25 \%$ \\
\hline Papel higiênico & $40,50 \%$ \\
\hline Caneta & $48,69 \%$ \\
\hline Papel sulfite & $38,97 \%$ \\
\hline Livros & $13,18 \%$ \\
\hline
\end{tabular}

Quadro 5 - Carga tributária "embutida" no preço final de alguns produtos

Fonte: "De olho no Imposto". Disp. em < http://www.deolhonoimposto.com.br/ >Acesso 05 dez 2009 
Importante frisar que, a par do instituto da seletividade, há, na legislação tributária em geral e na sobre ICMS, em particular, vários casos de isenção e imunidade. Exemplo disto é o contido no artigo 150 da $\mathrm{CF}$ :

Sem prejuízo de outras garantias asseguradas ao contribuinte, é vedado à União, aos Estados, ao Distrito Federal e aos Municípios: [...] VI - instituir impostos sobre: a) patrimônio, renda ou serviços, uns dos outros; b) templos de qualquer culto; c) patrimônio, renda ou serviços dos partidos políticos, inclusive suas fundações, das entidades sindicais dos trabalhadores, das instituições de educação e de assistência social, sem fins lucrativos, atendidos os requisitos da lei; d) livros, jornais, periódicos e o papel destinado a sua impressão.

Também surge a mesma imunidade no Art. 4 da Lei 11580/96-PR:

O imposto não incide sobre: I - operações com livros, jornais, periódicos e o papel destinado a sua impressão; II - operações e prestações que destinem ao exterior mercadorias, inclusive produtos primários e produtos industrializados semi-elaborados, ou serviços; III - operações interestaduais relativas a energia elétrica e petróleo, inclusive lubrificantes e combustíveis líquidos e gasosos dele derivados, quando destinados à industrialização ou à comercialização; IV - operações com ouro, quando definido em lei como ativo financeiro ou instrumento cambial [...].

As isenções de ICMS, segundo o que dispõe o inciso XII do Parágrafo Segundo do artigo 155 da Constituição Federal, foram remetidas à Lei Complementar. Esta fixou a competência aos Convênios do Senado Federal, por meio de decreto legislativo. Apesar de haver discussões sobre isenção e deliberação entre secretários de fazenda estaduais no CONFAZ - Conselho Nacional de Política Fazendária - apenas o poder legislativo pode conceder isenções de ICMS e as deliberações do CONFAZ extraem sua legitimidade de decreto legislativo que o criou.

No caso de Estados e Distrito Federal firmarem convênios de isenção recíproca de ICMS, tais convênios deverá ser ratificados pelos respectivos órgãos legislativos. Esclarecedoras, neste sentido, são as palavras de Carrazza (2003, p. 374), inspirado em lição de Geraldo Ataliba:

Prosseguindo o raciocínio do pranteado Mestre, os Estados e o Distrito Federal, querendo conceder isenções de ICMS, devem firmar entre si, por seus Executivos, convênios (pactos, acordos, contratos). Tais convênios, para se tornarem direito interno das unidades federativas interessadas, precisam ser ratificados, não por decreto do governador - como infelizmente vem acontecendo com base no art. 4 da Lei Com- 
plementar 24/75 - mas, sim, por meio de decreto legislativo baixado pela respectiva Assembléia Legislativa ou, no caso do Distrito Federal, por sua Câmara Legislativa. Repisamos que, por força do princípio da legalidade, o decreto legislativo (estadual e distrital) - lei em sentido material, como ensinava Pontes de Miranda - é que deve conceder isenções de ICMS. (Grifos no original).

Há também os casos de isenção em função de situação especial do contribuinte, como é o caso da isenção (ou alíquota zero) quando da compra de veículo por parte de detentores de necessidades especiais/deficiência física. Tal isenção foi concedida pelo CONFAZ, em sua 100a reunião extraordinária, realizada em Brasília, DF, no dia 19 de janeiro de 2007, que instituiu Convênio cuja Cláusula Primeira instrui:

Ficam isentas do ICMS as saídas internas e interestaduais de veículo automotor novo com características específicas para ser dirigido por motorista portador de deficiência física, desde que as respectivas operações de saída sejam amparadas por isenção do Imposto sobre Produtos Industrializados - IPI, nos termos da legislação federal vigente. $\S 1^{\circ} \mathrm{O}$ benefício correspondente deverá ser transferido ao adquirente do veículo, mediante redução no seu preço. $\S 2^{\circ} \mathrm{O}$ benefício previsto nesta cláusula somente se aplica a veículo automotor novo cujo preço de venda ao consumidor sugerido pelo fabricante, incluídos os tributos incidentes, não seja superior a R \$ 70.000,00 (setenta mil reais).

\section{A seletividade e as alíquotas interestaduais}

Pode-se também afirmar que a instituição das alíquotas interestaduais de ICMS guarda compatibilidade com o princípio da seletividade. Como pode ser visto no Quadro 5, a seguir, há diferença nas alíquotas em função dos estados de origem e de destino das mercadorias. Essa diferença "onera" os estados mais desenvolvidos, social e economicamente, ao mesmo tempo em que "gratifica" os estados menos desenvolvidos, da mesma perspectiva. Tal diferença é tanto aplicação da seletividade no sentido extrafiscal, visando à realização da tributação conforme a capacidade contributiva dos cidadãos, quanto uma tentativa de implantação da "federação de cooperação" prevista no Parágrafo Único do Artigo 23 da Constituição Federal. 


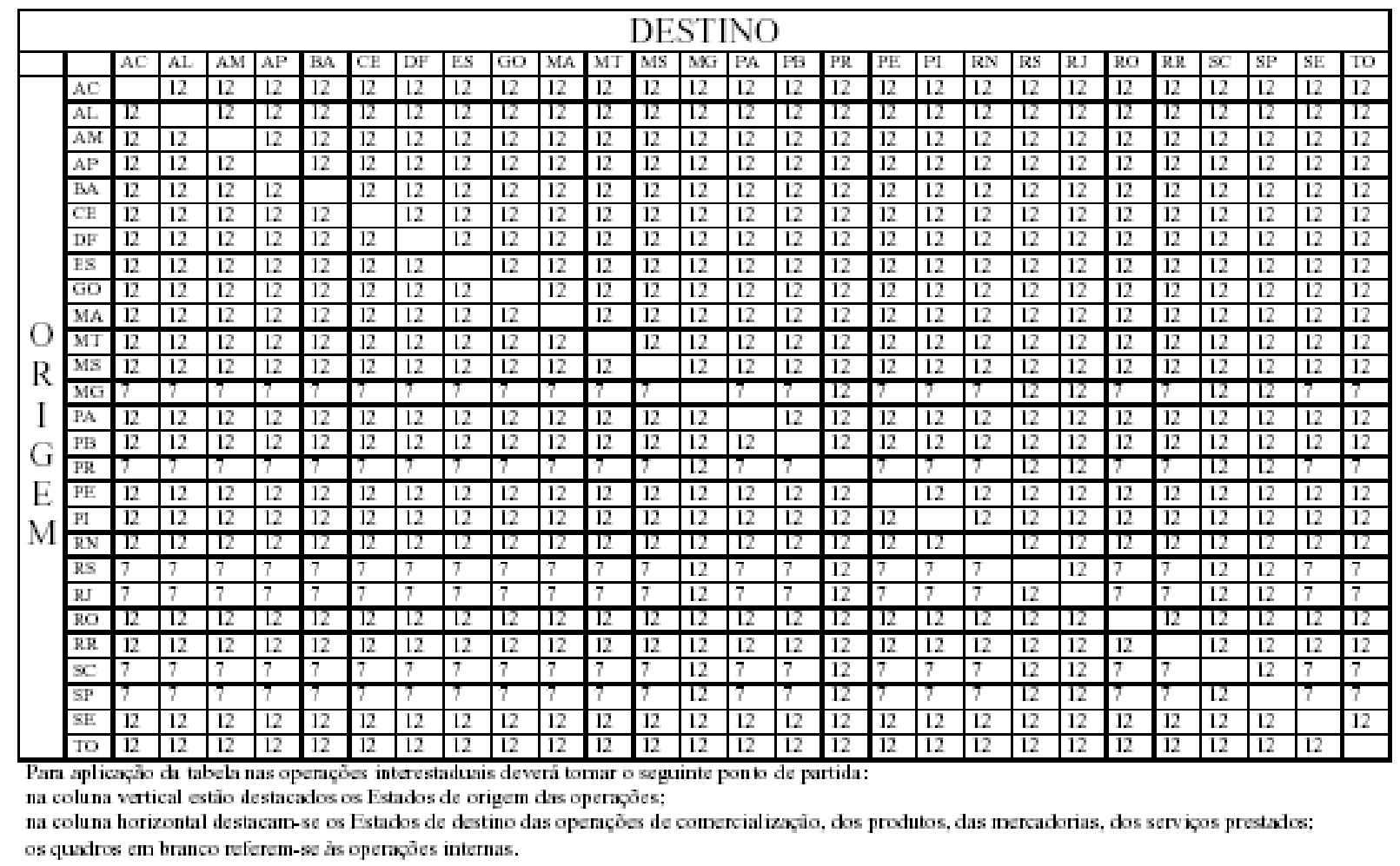

Quadro 6 - Alíquotas Interestaduais Fixadas por Resolução do Senado

\section{CONCLUSÃO}

Considerando-sequeoArtigo 145, parágrafo $1^{\circ} \mathrm{daCF} / 88$,impõeque, sempreque possível, os impostos terão caráter pessoal e serão graduados segundo a capacidade econômica do contribuinte, é de se afirmar que o instituto da seletividade (ou princípio, como advogam alguns) não está sujeito ao poder discricionário do legislativo ou do executivo e deve ser efetivado em sua plenitude.

A expressão "sempre que possível" no dispositivo constitucional faz lembrar as dificuldades de operacionalização do princípio da capacidade contributiva em impostos dinâmicos como o ICMS e o IPI. Mas tais dificuldades não podem servir de escusa ao Estado quando comete injustiças fiscais. Ainda que não se possa determinar a capacidade contributiva do cidadão que adquire bicicleta, por exemplo, há indícios razoáveis para se assumir que a capacidade contributiva do adquirente de um veículo com valor acima da média do valor daqueles denominados "veículos populares" tem mais capacidade contributiva do que o adquirente da bicicleta. Assumindo-se esta premissa, é possível fixar-se, seletivamente, alíquotas diferenciadas para os dois produtos e cumprir o princípio da capacidade contributiva. 
Da mesma forma, a pessoa que compra arroz pode ser a mesma que compra vinho de vinícola respeitada e de uma boa safra, mas, com certeza, há mais pessoas com capacidade financeira para comprar arroz do que pessoas que podem comprar bons vinhos - daí que não há justificativa aceitável para que ambos os produtos tenham a mesma alíquota de incidência de ICMS.

Do exposto, pode-se afirmar que a implantação da justiça tributária no Brasil está longe de estar concretizada, mas também se pode afirmar que o instituto da seletividade é um dos instrumentos que mais pode contribuir para que, ao menos, haja uma aproximação maior do ideal de justiça tributária delineado na Constituição Federal e que, a par de outras lutas ainda sendo travadas, o país alcance, futuramente, o estágio de ser, de fato, um Estado Democrático de Direito.

De qualquer forma, a comunidade jurídica, de acadêmicos a ministros dos tribunais superiores, deve estar - não só em função do disposto na Constituição Federal, mas também por representar o segmento social que mais proximidade tem com o tema - comprometida, primordialmente, com o ideal de justiça.

Ainda resta longo caminho a ser trilhado para que ele seja alcançado, mas é preciso que se continue buscando cumprir o ideal de justiça, no qual a justiça tributária tem papel fundamental.

\section{REFERÊNCIAS}

BALTHAZAR, Ubaldo César. O Tributo na história: da antiguidade à globalização. Florianópolis: Fundação Boiteux, 2006.

BOBBIO, Norberto. Teoria do ordenamento jurídico. 10. ed. Brasília: UNB, 2000.

CARRAZZA, Roque Antonio. Curso de direito constitucional tributário. São Paulo: Malheiros, 2002.

CARRAZZA, Roque Antonio. ICMS. São Paulo: Malheiros, 2003.

CARVALHO, Paulo de Barros. Curso de direito tributário. São Paulo: Saraiva, 2007.

CHIESA, Clélio. ICMS: sistema constitucional tributário: algumas inconstitucionalidades da LC 87/96. São Paulo: LTr, 1997.

JUDT, Tony. Pós-Guerra: uma história da Europa desde 1945. Rio de Janeiro: Objetiva, 2008. 
MENESCAL, Ana Mônica Filgueiras. A Seletividade como Instrumento Concretizador da Justiça Fiscal no Ambito do Icms. Fortaleza: Fundação Edson Queiroz, 2007. Disponível em: $<$ http://www.sefaz.ce.gov.br/content/aplicacao/internet/monografias/gerados/ana\%20monica\%20filgueiras\%20menescal.pdf > Acesso em: 15. nov. 2009.

SCHMITT, Antônio Ricardo Vasconcellos. Ativo permanente e ICMS. In: PEREIRA FILHO, Luiz Alberto Pereira (coord.). ICMS: Questões polêmicas. Curitiba: Juruá, 2005.

SOUZA, Rubens Gomes de. Estudos de direito tributário. São Paulo: Saraiva, 1950. 